\title{
Use of SPICES Model to Improve Family Medicine Residents Engagement in Clinical and Academic Teaching
}

\section{Ayman Afifi ${ }^{1 *}$, Tarek Elsaid ${ }^{1}$, Saad AlBattal ${ }^{1}$, Yaser Ebeid ${ }^{1}$, Abdel Majeed Elsheikh' $^{1}$, Maha Moharram ${ }^{1}$, Ghada AlArfaj1, Abood AlAbood1 , Abdelaziz AlRsheed1, Lamiaa Fiala ${ }^{2}$ and Mostafa Kofi ${ }^{1}$}

${ }^{1}$ Family Medicine Department, Prince Sultan Military Medical City, Riyadh, Saudi Arabia

${ }^{2}$ Department of Health Sciences, Faculty of Health and Rehabilitation Sciences,

Princess Nourah Bint Abdulrahman University, Riyadh, Saudi Arabia

*Corresponding Author: Ayman Afifi, Family Medicine Department, Prince Sultan

Military Medical City, Riyadh, Saudi Arabia
Received: October 28, 2021

Published: January 01, 2022

(C) All rights are reserved by Ayman Afifi., et al.

\section{Abstract}

This is an experience of applying certain degrees within the spectrum of the SPICES educational strategies in the advanced family medicine course at (R3) level of the Saudi family Medicine residency Program at Prince sultan Military Medical city (PSMMC), Riyadh, Saudi Arabia. We applied multiple interventions to approach elements of the "SPICES Model were used to" increase residents' engagement, interest and their active participation within a previously perceived very tough course at the $3^{\text {rd }}$ year residency level. We were also very keen to ensure matching of the course objectives and we used triangulation of data collection tools to oversee and attain that. 2 open Focus group discussion were conducted, 5 active relevant field visits were completed, and more than 150 feedback responses were received from 16 residents continuously all through the 8 weeks of the course with an $80 \%$ response rate and a satisfaction rate that exceeds $84 \%$ plus matching the ILOs that exceeds $80 \%$. The voice of the trainers was not overlooked in our study. These interventions were the nucleus to Spread the culture of active learning between both the trainees and the trainers -in our institution- through many techniques and models like in SPICES strategies and many others.

Keywords: Family Medicine Residents; SPICES Educational Strategies; Residents' Engagement

\section{Introduction}

There has been almost always a great challenge for all the medical instructors on any educational level either under or postgraduate; this is how to motivate and engage their learners to initiate and keep active and interesting learning. Many educational techniques came to conquer this challenge like: Flipped Learning, Team-Based learning, Technology-enhanced Learning and Hybrid Learning. All of them are depending on many educational principles and strategies that foster and improve students' commitment of to actively learn; ex: Student-centered approach, the problem-based strategy, beside adding the concept of elective learning.

Six educational strategies have been identified -since more than 35 years- relating to the curriculum in a medical school (SPICES Model, Harden., et al. 1984) [1]. Each issue can be represented as a spectrum or continuum: student-centered on one edge Vs teach- er-centered on the other edge, problem-based vs informationgathering, integrated Vs. discipline-based, community-based Vs hospital-based, elective Vs uniform and systematic Vs apprenticeship- based. The factors supporting a move towards each end of the

Figure 1: Educational strategies spectrum [2]. 
New curriculum developers tend to trend to left side of the continuum, while traditional curiculum developers and implementers tend to right side of the continuum $[1,3,4]$.

The SPICES analytical technique described is useful in several situations: [5]

- Mostly related to tackling specific issues relating to development of a new curriculum or syllabus or reviewing of an existing one by an assigned committee especially when it comes to the intended objectives or aim of the course or subject.

- Decisions about teaching methods. Decisions in relation to each of the Spices issues have implications for teaching methods within the school. For example, a more studentcentered curriculum will require access to resource material and the organization of small group work.

- Decisions about assessment. Consideration of the issues may also provide pointers to the most appropriate methods of assessment. For example, a community orientation should be reflected in the assessment procedures and integrated courses should not be assessed by disciplinebased examination.

The SPICES model was utilized by Clinical Squadron, 22 Field Hospital to evaluate its clinical development program. This program was designed to provide affordable, balanced, and coherent practice-based clinical learning for all levels of healthcare providers and associated support staff to ensure operational capability, which would ultimately enable the Commanding Officer to achieve mission success. Although it was believed that the program was innovative and compared favorably when benchmarked against similar programs implemented by another Regular Army field hospitals, the SPICES model identified areas where changes to delivery and direction would improve the program's effectiveness [10].

This paper is a bout an experience of applying certain degrees within the spectrum of the "SPICES Model" through the advanced Course at residency level three (R3) level of the Saudi family Medicine residency Program [11] at Family Medicine Administration, Prince sultan Military Medical city (PSMMC), Riyadh Military Hospital, Saudi Arabia.

From our past experiences (2014-2017) for the Advanced Family Medicine Course, we noticed low level of attendance and interest among family Medicine residents. The course was conducted for 8 weeks in a typical traditional way; teacher centered, didactic lecture-based, busy schedule trying to cover so many topics that were missed within the routine family medicine clinical rotations; themes like environmental and occupational health, school health program, nutrition, adolescent health, health administration, and quality assurance were run by the experts of each field, many of them may be away from the family medicine perspectives. Also, we were not sure about the achieving of the course' objectives (ILOs) by the different speakers (about 40 speakers) from diverse subspecialties and different backgrounds. Another very important point; there were no sort of structured feedback to build upon for the progress of the coming years.

\section{Methods}

Study area

Al-Wazarat Health center, which is the main center under Family Medicine Administration, PSMMC that offer Health Care services for military Patients and their family for a target population of more than half million and it also offer the main center for training of the Saudi family Medicine residents with all the needed resources and facilities for that serve and support educational climate.

\section{Setting}

During conducting the advanced Family Medicine Module within the third year of the residency program (R3 Level). This course was intended mainly in the previous Curriculum (2011 and 2014) for 6-8 wks. to complement any missing themes related to family Medicine that were not covered during their hospital rotation (Syllabus attached). From our experience with this course, it was run mainly as lecture-based by speakers from diverse departments and many concerns were raised at this time regarding residents' satisfaction, participation and even their attendance. Also, we were not sure about achieving the ILOs. that were already mentioned inside the Curriculum, or even many speakers going beyond the scope of Family Medicine. The whole grade of the course was totally through end of course exam (MCQs) with passing score of $60 \%$.

\section{Subjects}

Saudi Residents (R3 level), during academic year 2018 and 2019 (each of them for 8 weeks).

N.B; The old Saudi Family Medicine Residency program till 2019 was on a 4-year duration, currently with the new Curriculum of 2020 , it has been reduced to 3 years duration with a reduction of duration of many courses like the advanced course and integrate its topics within the 3 years duration themes 


\section{Study design}

Mixed study type: using both qualitative tool (2 Focus Group with Residents and Unstructured Interview with the speakers), this was triangulated even with many occasions for observations by the main researcher and the co-researchers, and documenting the active participation, the small group dynamics through photo capturing sometimes. A quantitative tool like the overall satisfaction rate from the feedback questionnaire, and their final marks with the passing score (comparing that with previous years (20152017) for the same course.

\section{Our intervention}

The following measures were implemented: 1) Automated Email Machine subscription that allowed automated email delivery to the speakers 5 - 6 wks. before their talks and to the residents 1 wk. before each week activity. These emails containing all the Intended Learning outcomes by the end of each topic and highlight the importance of active learning giving many examples for many educational techniques (including Problem-solving scenarios). 2) Google Forms were sent by the end of every week containing assessment for their satisfaction about achieving the objectives and about the speakers, these forms were closed 3 days after the activity. 3) A concept of elective (assignment, topic, and time) was introduced and given $40 \%$ from the final mark, where a free space was left for their innovation under guidance of multiple couches. 4) Also, all the field visits that are relevant to the course contents were coordinated. 5) 2 Focus Group discussion were completed, one within the middle of the course and one at the end, addressing themes like; what did you like best, Least, and why and what can you suggest for the coming courses about each of our major interventions (above). 6) A special committee was formed to follow the progress of the course and the application of the above steps.

\section{Statistical analysis}

Descriptive data analysis using SPSS, version 22.

\section{Ethical consideration}

- IRB Approval: 1432

- Taking consent from the residents for any photo taken

- Informing residents and Speakers about our aim and intervention

\section{Results}

30 speakers have been contacted through the automated email machine 4 - 6 wks. ahead before their assigned speech and we re- ceived emails containing their response with their ppt before their talks 1 - 2 wks before as agreed from about one third of them. Most of them gave us particularly good positive feedback for the course preparation and the residents' attendance and interest.

five-very relevant- fields' visits were run through the courses, also an elective item were introduced through the elective timing or the elective topics: they had the chance to freely choose for their assignment, a free session weekly either to stay for team working or to go home with option of contact between them, also a vacant session within the syllabus to suggest a topic of their interest either related or not related to the course, beside and this was for the $1^{\text {st }}$ time applied, we added clinical duties twice weekly within the course the final marks were as follow: $60 \%$ for the final exam, $10 \%$ for the attendance and the feedbacks, $30 \%$ for the assignment and the passing score was $70 \%$, we had 1 failure (number 16 was not attending or participating regularly and withhold from attending the final exam).

For the residents, we were sending them the intending learning outcomes $1 \mathrm{wk}$. before and then immediately we were waiting for 3 days for the written feedback, we received about 150 written responses (between the qualitative and the quantitative data). all over the course the medium satisfaction rate was $>84 \%$ and more than $80 \%$ of the speakers or the sessions matched the objectives of the Saudi commission. Attendance rate exceeded $80 \%$. We were receiving weakly on average 12-13 written feedback out of 15 residents (in 2019 course) with a response rate that exceeds $84 \%$.

For the 2 Focus Group discussions (each for about one hour conducted by 2 different co-authors and the main author was the scribal), we received from the entire group very encouraging feedback quotes (available). Also 2 short observation visits were done by the researchers and many photos for the small group dynamics was captured.

The insertion of elective concept within our course came up with very good results either in the elective assignments, which came up with innovative idea from this new generations, they really were exceptionally interested, sitting longer time together without being mandated to come up with interesting short educational videos (available) either to the public or to the junior doctors which have been used by our family medicine department and by the Academic and training division also. Also, the elective timing and topics, their choice to have a clinical duty one session to one day per week have a great impact in changing the pure academic atmosphere of the 
advanced course in the previous years, it gives more a sensation of movement, feeling free and applying what they learn theoretically, this free time to choose gave them the chance either to choose clinical topics with an expert available to talk on request or practice what they learn to their top priority which is the clinic duty. Making clinical duty as a choice for 8 wks. made them practice clinic with love, passionate choice after heavy academic days.

\section{Discussion}

"Active Learning is the grand meta-principle in education" [12], especially when it comes to adult education to help fostering deep learning and Life-Long Learning attitude. In our case study, with the help of our highly focusing program director and his deputy, we critiqued our educational situation for the sake of better learning not due to any external factor, we noticed how much the old advanced course was conducted far away from the new educational techniques and modalities, yes our residents were passing the end of course exam and there was no significant difference in the final passing score before or after our interventions, but now we came closer to our residents, we touching their progress, listening to their voices, we can see now when and how they are enjoying learning experience. Towards taking our residents' learning seriously is our approach [13]. As an indirect consequence, all through the implementation of this project, other active projects started and many new techniques of active learning are currently used, like the elective assignments, field visits, volunteering, system for feedback, beside others like flipped classroom, this is plus inclusion academic with clinical duties together especially with the new Saudi Curriculum for family Medicine Residency Program that started November, 2019, also TOT (Training of the Trainers) sessions every now and then with a process of filtering for the trainers based upon the received feedback and also based upon their interest in attending or applying new educational techniques. and then before the academic years for the rest of the trainers a plan of annual TOT series (even for other hospital department) of targeted sessions for the blended learning and TEL was decided about these educational techniques.

We confess many limitations in our case study like the small number of residents, and no statistical analysis was performed to the feedback from the speakers or the 2 focus groups with the residents.

\begin{tabular}{|c|c|c|c|c|c|c|c|c|c|c|c|}
\hline \multirow{3}{*}{ Items } & \multicolumn{11}{|c|}{ No. of received Feedback (\% excluding the "missing") } \\
\hline & \multicolumn{2}{|c|}{ Very Unsatisfied } & \multicolumn{2}{|c|}{ Unsatisfied } & \multicolumn{2}{|c|}{ Neutral } & \multicolumn{2}{|c|}{ Satisfied } & \multicolumn{2}{|c|}{ Very Satisfied } & \multirow{2}{*}{ Missing } \\
\hline & No. & $\%$ & No. & $\%$ & No. & $\%$ & No. & $\%$ & No. & $\%$ & \\
\hline Week 1 & 2 & 0.9 & 7 & 3.0 & 27 & 11.5 & 90 & 38.5 & 108 & 46.2 & 4 \\
\hline Week 2 & 0 & 0 & 5 & 2.5 & 39 & 19.5 & 81 & 40.5 & 75 & 37.5 & 8 \\
\hline Week 3 & 1 & 0.4 & 11 & 4.0 & 16 & 5.9 & 91 & 33.5 & 153 & 56.3 & 0 \\
\hline Week 5 & 2 & 1.0 & 4 & 2.1 & 30 & 15.5 & 89 & 45.9 & 69 & 35.6 & 1 \\
\hline Week 6 & 0 & 0 & 3 & 2.6 & 17 & 14.5 & 31 & 26.5 & 66 & 56.4 & 0 \\
\hline Week 7 & 0 & 0.0 & 1 & 1.2 & 9 & 10.8 & 21 & 25.3 & 52 & 62.7 & 1 \\
\hline \multirow[t]{2}{*}{ Total } & 5 & $0.45 \%$ & 31 & $2.8 \%$ & 138 & $12.5 \%$ & 403 & $36.6 \%$ & 523 & $47.58 \%$ & 14 \\
\hline & & \multicolumn{2}{|c|}{$3.25 \%$} & & & $12.5 \%$ & & \multicolumn{2}{|c|}{$84.2 \%$} & & \\
\hline
\end{tabular}

Table 1: Total received feedback by weeks.

\begin{tabular}{|l|c|c|c|c|c|c|}
\hline \multicolumn{7}{|c|}{ Assessment } \\
\hline \multirow{2}{*}{ Wks. } & \multicolumn{2}{|c|}{ Unsatisfied } & \multicolumn{2}{c|}{ Neutral } & \multicolumn{2}{c|}{ Satisfied } \\
\cline { 2 - 7 } & No. & (\%) & No. & (\%) & No. & (\%) \\
\hline 1 & 9 & 3.8 & 27 & 11.5 & 198 & 84.6 \\
\hline 2 & 5 & 2.5 & 39 & 19.5 & 156 & 78.0 \\
\hline 3 & 12 & 7.0 & 16 & 9.3 & 144 & 83.7 \\
\hline 5 & 6 & 3.1 & 30 & 15.5 & 158 & 81.4 \\
\hline 6 & 3 & 2.6 & 17 & 14.5 & 97 & 82.9 \\
\hline 7 & 1 & 1.2 & 9 & 10.8 & 73 & 88.0 \\
\hline Total & $36(3.6 \%)$ & $138(13.8 \%)$ & $826(82.6 \%)$ \\
\hline
\end{tabular}

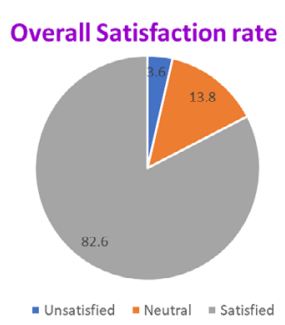

Figure 2: Overall satisfaction.

Table 2: Percent of satisfaction by week and overall. 


\begin{tabular}{|c|c|c|c|c|}
\hline \multicolumn{5}{|c|}{ Scores of Satisfactions } \\
\hline \multicolumn{2}{|l|}{ Wks. } & Mean & SD & Median \\
\hline \multirow{2}{*}{1} & Overall & 4.4 & 0.2 & 4.4 \\
\hline & Objectives & 4.3 & 0.2 & 4.4 \\
\hline \multirow{2}{*}{2} & Overall & 4.1 & 0.2 & 4.1 \\
\hline & Objectives & 4 & 0.2 & 4 \\
\hline \multirow{2}{*}{3} & Overall & 4.4 & 0.2 & 4.4 \\
\hline & Objectives & 4.3 & 0.2 & 4.4 \\
\hline \multirow{2}{*}{5} & Overall & 4.1 & 0.3 & 4.2 \\
\hline & Objectives & 4.1 & 0.2 & 4.2 \\
\hline \multirow{2}{*}{6} & Overall & 4.4 & 0.3 & 4.4 \\
\hline & Objectives & 4.4 & 0.2 & 4.4 \\
\hline \multirow{2}{*}{7} & Overall & 4.5 & 0.4 & 4.5 \\
\hline & Objectives & 4.3 & 0.4 & 4.5 \\
\hline \multirow{2}{*}{ Total } & Overall & 4.3 & 0.3 & 4.3 \\
\hline & Objectives & 4.2 & 0.3 & 4.2 \\
\hline
\end{tabular}

Table 3: Overall mean scores of satisfactions.

\begin{tabular}{|c|c|}
\hline Year & Grades \\
\hline 2018 & $83.3 \%$ \\
\hline 2017 & 77.5 \\
\hline
\end{tabular}

Table 4: Mean of Scores of residents -in the end of course exam- before and after application of our intervention.

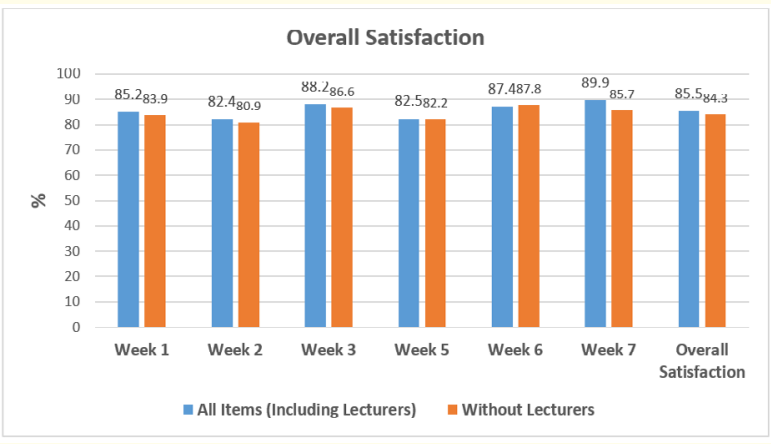

Figure 3: Overall (and weekly) satisfaction and satisfaction about trainers as received from residents' feedback.

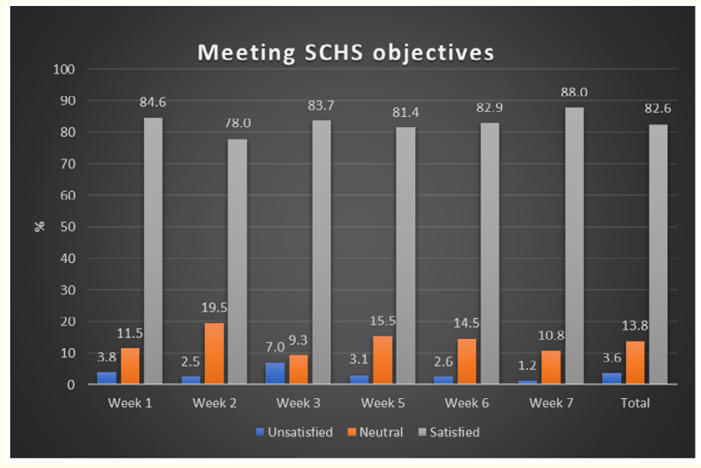

Figure 4: Percent of matching the ILOs as evaluated by the residents.

\section{Conclusions}

We succeeded to engage our target residents, more than the previous years, in spite that we do not have the complete adequate measures for this, but we will build upon what we achieved with the team spirit that we got and the good planning that we realized.

\section{Bibliography}

1. Harden RM. "Educational strategies in curriculum development: the SPICES model". Medical Education 18.4 (1984): 284297.

2. John A Dent. "Using the SPICES model to develop innovative teaching opportunities in ambulatory care venues". Korean Journal of Medical Education 26.1 (2004).

3. Kearsley G Andragogy (M. Knowles). "The theory into practice database" (2010).

4. RM Harden., et al. "Task-based learning: the answer to integration and problem-based learning in the clinical years". Medical Education 34 (2000): 391-397.

5. General Medical Council. "Tomorrow's doctors: Recommendations on undergraduate medical education". London: General Medical Council (1993).

6. Walton HJ. "Proceedings of the World Summit on Medical Education". Medical Education 28.1 (1993): 140-149.

7. Anderson MB and Swanson AG. "Educating medical students, the ASME-TRI report with supplements". Academic Medicine 68 (1993): S1-46. 
8. Kar SS., et al. "Student Centered Learning in community Medicine: An experience from Jwaharlal institute of Postgraduate Medical Education and Research". The National Medical Journal of India 27.5 (2004): 272-276.

9. Harden RM., et al. "Educational strategies in curriculum development: the SPICES model. ASME Medical Education Booklet number 18". Medical Education 18 (1984): 284-297.

10. Major David Bate. "Utilizing the SPICES model to evaluate the continuous improvement of a clinical development program facilitated by Clinical Squadron, 22 Field Hospital”. Medical Teacher 25.5 (2003): 551.

11. Saudi Board for Family Medicine Curriculum, SCHS (2016).

12. Cross K Patricia. "What do we know about students' learning and how do we know it?" UK Berkeley center for studies in higher education (2005).

13. Mary Anne Heng., et al. Towards a practice of taking students learning seriously. In book: "Curriculum leadership by middle leaders: Theory, design and practice". Edition: 1Publisher: Routledge Editors (2018).

\section{Assets from publication with us}

- Prompt Acknowledgement after receiving the article

- Thorough Double blinded peer review

- Rapid Publication

- Issue of Publication Certificate

- High visibility of your Published work

Website: www.actascientific.com/

Submit Article: www.actascientific.com/submission.php

Email us: editor@actascientific.com

Contact us: +919182824667 